\title{
Effects of a simple prototype respiratory muscle trainer on respiratory muscle strength, quality of life and dyspnea, and oxidative stress in COPD patients: a preliminary study
}

\author{
This article was published in the following Dove Press journal: \\ International Journal of COPD \\ 12 May 2017 \\ Number of times this article has been viewed
}

\author{
Jirakrit Leelarungrayub' \\ Decha Pinkaew' \\ Rungthip Puntumetakul ${ }^{2}$ \\ Jakkrit Klaphajone ${ }^{3}$ \\ 'Department of Physical Therapy, \\ Faculty of Associated Medical \\ Sciences, Chiang Mai University, \\ Chiang Mai, ${ }^{2}$ Research Center in Back, \\ Neck, Other Joint Pain and Human \\ Performance (BNOJPH), Khon Kaen \\ University, Khon Kaen, ${ }^{3}$ Department \\ of Rehabilitation Medicine, Faculty \\ of Medicine, Chiang Mai University, \\ Chiang Mai, Thailand
}

Background: The aim of this study was to evaluate the efficiency of a simple prototype device for training respiratory muscles in lung function, respiratory muscle strength, walking capacity, quality of life (QOL), dyspnea, and oxidative stress in patients with COPD.

Methods: Thirty COPD patients with moderate severity of the disease were randomized into three groups: control ( $n=10,6$ males and 4 females), standard training ( $n=10,4$ males and 6 females), and prototype device ( $n=10,5$ males and 5 females). Respiratory muscle strength (maximal inspiratory pressure [PImax] and maximal expiratory pressure [PEmax]), lung function (forced vital capacity [FVC], percentage of FVC, forced expiratory volume in 1 second $\left[\mathrm{FEV}_{1}\right]$, percentage of $\mathrm{FEV}_{1}\left[\mathrm{FEV}_{1} \%\right.$ ], and $\left.\mathrm{FEV}_{1} / \mathrm{FVC}\right), 6$-minute walking distance (6MWD), QOL, and oxidative stress markers (total antioxidant capacity [TAC]), glutathione (GSH), malondialdehyde (MDA), and nitric oxide (NO) were evaluated before and after 6 weeks of training. Moreover, dyspnea scores were assessed before; during week 2, 4, and 6 of training; and at rest after training.

Results: All parameters between the groups had no statistical difference before training, and no statistical change in the control group after week 6. FVC, FEV $/$ FVC, PImax, PEmax, QOL, MDA, and NO showed significant changes after 6 weeks of training with either the standard or prototype device, compared to pre-training. $\mathrm{FEV}_{1}, \mathrm{FEV}_{1} \%, 6 \mathrm{MWD}, \mathrm{TAC}$, and GSH data did not change statistically. Furthermore, the results of significant changes in all parameters were not statistically different between training groups using the standard and prototype device. The peak dyspnea scores increased significantly in week 4 and 6 when applying the standard or prototype device, and then lowered significantly at rest after 6 weeks of training, compared to pre-training.

Conclusion: This study proposes that a simple prototype device can be used clinically in COPD patients as a standard device to train respiratory muscles, improving lung function and QOL, as well as involving MDA and NO levels.

Keywords: prototype simple training device, PImax, lung function, quality of life, oxidative stress, COPD

\section{Introduction}

Today, the high impact of COPD has been suggested as a major cause of chronic morbidity and mortality worldwide, ${ }^{1}$ and is expected to increase rapidly in Thailand, especially among rural and urban communities in Chiang Mai Province. ${ }^{2}$ Strong 
evidence has reported that the pathophysiological changes relate to an imbalance between oxidant and antioxidant status from chronic infection, as is the case in COPD. ${ }^{3,4}$ Thus, a high level of malondialdehyde (MDA) from lipid peroxidation and low level of glutathione (GSH), or total antioxidant capacity (TAC), has been found in COPD patients. ${ }^{5,6}$ Although there is less evidence to confirm the relationship between the imbalance of oxidative stress and physical function, severe and dominant skeletal dysfunction, muscle atrophy, sarcopenia, weight loss, and catabolic status have been reported. ${ }^{7,8}$ However, previous evidence has shown that diaphragmatic skeletal muscles can generate free radicals under various stressful conditions, such as hypoxia, exercise, or a hot environment. ${ }^{9}$ Previous evidence proved that overexpression of tumor necrotic factor-alpha in the lungs could induce the release of superoxide radicals in the muscles and demonstrate significantly reduced fatigue resistance, ${ }^{10}$ including hypoxemia that can induce reactive oxygen species (ROS) formation. ${ }^{11}$ Moreover, low physical activity levels with limitations from dyspnea, skeletal muscle deconditioning and high ROS have impacted negatively on health-related quality of life (HRQoL). ${ }^{12}$ Therefore, overall deconditioning demonstrates in most COPD patients. Thus, recovery from physical and pulmonary decondition with medical treatment is necessary. A study in 2009 showed that pulmonary rehabilitation was highly effective in improving the exercise capacity with lower dyspnea and better quality of life (QOL) for COPD patients. ${ }^{13}$

The pulmonary rehabilitation program includes various techniques such as airway clearance, breathing exercise, chest mobilization, and exercise. ${ }^{14,15}$ Moreover, the strengthening exercise program of moderate intensity for both general and respiratory muscles has been included in the standard pulmonary rehabilitation program, which suggests that better tolerance of physical exercise is concomitant with a decrease in exercise-induced oxidative stress damage. ${ }^{2,16}$ For example, previous studies found that acute exercise with a cycle ergometer induced oxidized GSH (GSSG) ${ }^{17}$ and MDA levels after a graded exercise test. ${ }^{18}$ Most techniques, including respiratory muscle training (RMT), are very important for improving symptoms in COPD patients, as some reported reviews on the clinical signs and symptoms from diaphragm or intercostal muscle weakness have indicated that dyspnea, tachypnea, use of accessory muscles, and paradoxical movement are presented in COPD patients. ${ }^{19,20}$ A systematic review by Geddes et $\mathrm{al}^{19}$ suggested that RMT, with an inspiratory threshold loading device, can be applied with a varied protocol, such as 1-5 daily sessions of 15-30 minutes for a 5- to 10-week period. Then, inspiratory muscle strength increases significantly after maximal inspiratory pressure (PImax), and lung volume increases by forced vital capacity (FVC), or forced expiratory volume of 1 second $\left(\mathrm{FEV}_{1}\right)$, which improves exercise capacity, releases dyspnea, and improves QOL. ${ }^{19}$ Therefore, RMT has been proposed as beneficial directly to the respiratory muscles, as well as exercise tolerance and QOL. There are many commercial products currently available worldwide such as the POWERbreathe ${ }^{\circledR}$ (POWERbreathe International Ltd) or Threshold ${ }^{\circledR}$ device (Respironics Inc.), although POWERbreathe ${ }^{\circledR}$ can set resistance at a different loading of $17-274 \mathrm{cmH}_{2} \mathrm{O}$ (UK National Health Service prescription). ${ }^{21}$ In addition, the Inspiratory Muscle Trainer device (Smiths Medical ASD, Inc., USA) with six different color-coded resistors and a central hole of 2-7 $\mathrm{mm}$ diameter also can be used. However, the high price of both these devices (for example, US\$ 299-359 for POWERbreathe ${ }^{\circledR}$ or US\$ 36 for Inspiratory Muscle Trainer) may be prohibitive in using the devices in many developing countries, including Thailand. Therefore, an interesting idea was to develop an inexpensive prototype device from a plastic water pipe made from polyvinyl chloride (PVC) and a plastic cap, as an individual method for training respiratory muscles. Therefore, the aim of this study was to compare the efficiency of a simple prototype device with preliminary results from a standard device for future clinical application in COPD patients, and show how the former can be equally beneficial in improving pulmonary function, respiratory muscle strength, QOL, and walking capacity, as well as oxidative stress and dyspnea outcomes. The hypothesis of this preliminary study assumed that an application with a prototype simple device should provide the same clinical benefits as provided by the standard device training.

\section{Methods}

This study was approved by the Ethic Human Committee at the Faculty of Associated Medical Sciences, Chiang Mai University, Thailand (AMSEC-59EX-009), and permission to study was granted by a physician at Sansai Hospital, Sansai, Chiang Mai Province, Thailand. It was conducted in accordance with the Declaration of Helsinki, and all the participants provided written informed consent.

\section{Experimental and subject design}

Beaumont et $\mathrm{al}^{22}$ designed a clinical trial on RMT in 34 COPD patients, with 16 in the training group and 18 in the control group, and the results showed improved $\mathrm{FEV}_{1}$ in the 
training group. This study was conducted at Sansai Hospital, which had 75 COPD outpatients at COPD Clinic. However, 36 patients diagnosed as having moderately severe COPD were investigated by following the guideline of the Global Initiative for Chronic Obstructive Lung Disease (GOLD) in stage II, based on the values of between 50 and $70 \%$ predicted $\mathrm{FEV}_{1}$, and the ratio of $\mathrm{FEV}_{1} / \mathrm{FVC}_{\text {was }}<0.7 .{ }^{23}$

A total of 36 male and female COPD patients, aged between 45 and 80 years, with moderately stable COPD volunteered for this study. They were located at home and had had their health followed up continuously at Sansai Hospital, Chiang Mai Province, Thailand. In order to achieve accurate results and a good comparative design, all the subjects (18 males and 18 females) were randomly divided into three groups with matching stages: control $(n=12 ; 6$ males and 6 females), standard RMT device $(\mathrm{n}=12 ; 6$ males and 6 females), and prototype RMT device ( $n=12 ; 6$ males and 6 females). Furthermore, the patients received medication in the form of either a long-acting inhaled bronchodilator or a long-acting inhaled steroid, according to GOLD recommendations. All of the subjects were ex-smokers and had a stable clinical condition during the experiments. If they showed uncontrolled hypertension, unstable cardiac disease, recurrent symptoms of pneumothorax, thoracic or chest pain including neuromuscular disorders, liver diseases or endocrinal abnormalities, they were excluded from this study. Moreover, subjects taking supplements or any nutrients such as vitamins or $\mathrm{N}$-acetylcysteine compounds during this study were also excluded from the study. All the subjects signed a written consent form before the program started.

Baseline assessment, including a thorough history interview and assessment of characteristics such as height, weight, and body mass index (BMI), as well as basic screening for health status, with a complete blood count, was carried out in all the subjects. They were then evaluated by the pulmonary function test (PFT), using a spirometer
(HI-105, CHEST M.I., Inc, Japan), for testing the respiratory muscle strength from PImax and maximal expiratory pressure (PEmax) (MicroRPM; Micro Medical Ltd, Kent, UK), with assessments made from 6-minute walking distance (6MWD) test, and QOL by using a clinical COPD questionnaire (CCQ). In addition to pre-evaluating oxidative stress markers of TAC, GSH, MDA, and nitric oxide (NO) from venous blood, all parameters (PFT, PImax, PEmax, 6MWD, QOL, TAC, GSH, MDA, and NO) were re-evaluated after 4 weeks of experiments. Furthermore, the peak dyspnea scores at rest before training; during the use of RMT devices at week 2, 4, and 6; and at rest after completing the study were taken using the Borg scale (0-10 scale).

\section{Standard and prototype RMT devices}

The standard respiratory muscle trainer $\left(\right.$ Portex $\left.^{\circledR}\right)$ purchased from Smiths Medical ASD, Inc. had a one-way valve controlling system with six resistors of different diameters $(2-7 \mathrm{~mm}$ diameter) (Figure 1A). A simple prototype device was produced preliminarily by adapting a plastic water pipe $(2 \mathrm{~cm}$ in diameter) made from PVC. This simple design had two components: an $11 \mathrm{~cm}$ long PVC tube and plastic caps bought from a local market in Chiang Mai Province, Thailand. One end of the PVC tube ( $3 \mathrm{~cm}$ in length) was modified into a plate-shaped mouth panel by heating before compression using a mechanical compressor, with a steel plat fixed within the mouth of the PVC tube for controlling the final shape of the plat mouth. Then, the plat mouth was smoothed with sandpaper. The plastic caps had a small 2, 4, or $6 \mathrm{~mm}$ diameter hole drilled centrally using an electric drill, and were coated with different colors (red, blue, and gray) before inserting into the opposite end of the tube (Figure 1B).

\section{RMT program}

The standard or simple prototype RMT device, with plastic caps having different sized holes $(6,4$, and $2 \mathrm{~mm}$ diameter $)$,
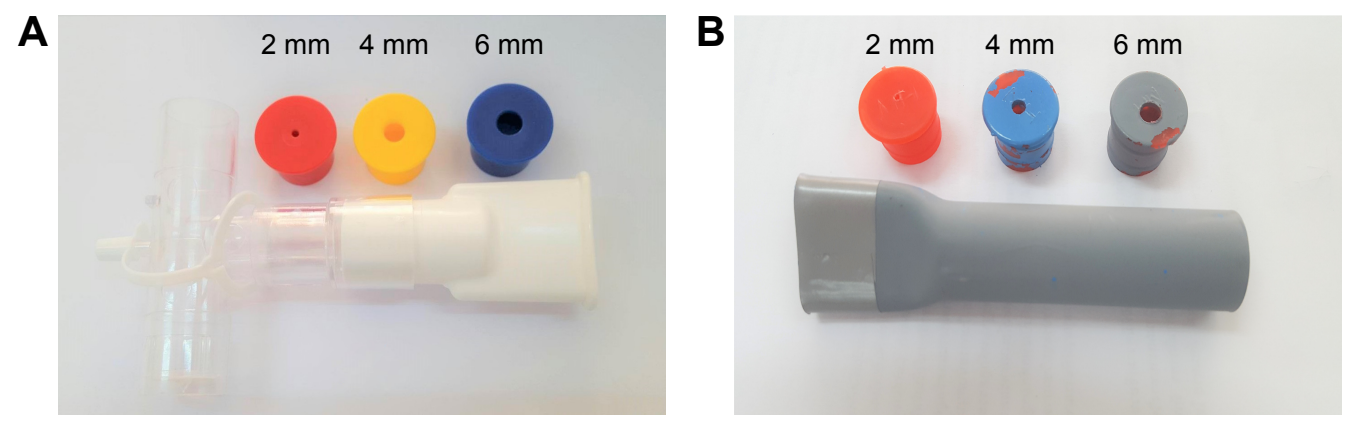

Figure I Standard RMT device (Smiths Medical ASD, Inc.) (A) and a prototype respiratory muscle trainer with PVC plastic water pipe and plastic caps (B). Abbreviations: RMT, respiratory muscle training; PVC, polyvinyl chloride. 
was selected for both the training groups, which started inspiration through a $6 \mathrm{~mm}$ hole once daily for the first 2 weeks, before changing to $4 \mathrm{~mm}$ and $2 \mathrm{~mm}$ holes in the second and fourth week, respectively. Thirty slowly repeated inspirations passed through the device, with a 3-minute interval of rest in each of four training sessions; thus, 20-30 minutes of RMT was completed. The subjects initiated each inspiratory effort from residual volume and stroke in order to maximize the inspiratory volume. This RMT protocol is known to be effective and has been proposed to elicit an adaptive response. ${ }^{24}$ Therefore, 120 inspirations in a device with 3 resting intervals were performed in both the standard and simple prototype RMT groups.

\section{Outcome measurements}

\section{Pulmonary function test}

FVC, percentage of forced vital capacity $(\mathrm{FVC} \%), \mathrm{FEV}_{1}$, and percentage of $\mathrm{FEV}_{1}\left(\mathrm{FEV}_{1} \%\right)$ were compared with the predicted normal values, with the $\mathrm{FEV}_{1} / \mathrm{FVC}$ ratio evaluated from the FVC maneuver in pneumatic-flow sensor spirometry (HI-105), performed under instructions of the American Thoracic Society (ATS) PFT. ${ }^{25}$ All the participants were seated wearing nose clips as required. Careful instructions and coaching were given to prevent air leaks around the mouthpiece and support the cheeks during the test. Three slow, normal breaths were taken before performing maximal inhalation and exhalation and returning to normal breath, and all data were printed from a spirometer (CHESTGRAPH HI-105; CHEST M.I., Inc, Tokyo, Japan) after the test was completed. The highest value was selected in liter and percentage of $\mathrm{FVC}, \mathrm{FEV}_{1}$, or $\mathrm{FEV}_{1} / \mathrm{FVC}$ ratio from three repeated measurements, with not more than eight tests.

\section{Respiratory muscle strength test}

Respiratory muscle strength was assessed by measuring the maximal inspiratory mouth pressure (MIP) at residual volume and PEmax maximal inspiratory mouth pressure at full inspiratory volume in sitting position, using a portable hand-held mouth pressure meter (MicroRPM). All the participants were seated wearing nose clips as required in order to prevent air leaks, and the flank mouthpiece was used. A sharp, forceful effort was maintained in each test for a minimum of 2-3 seconds, and the highest data output expressed in $\mathrm{cmH}_{2} \mathrm{O}$ from three repeated evaluations was selected.

\section{Six-minute walking distance test}

The test for 6MWD was a standardized guide from the ATS protocol, ${ }^{26}$ which was modified from the $20 \mathrm{~m}$ straight walking test performed in an outside corridor. Any vigorous physical activities and eating 2 hours before starting the 6MWD were avoided. Comfortable clothes and shoes could be worn during the test. Vital signs such as heart rate, blood pressure, respiratory rate, and oxygen saturation were evaluated for safety reasons before and after the test. The subjects were asked to walk for 6 minutes at their fastest pace for the longest possible distance under the supervision of a physiotherapist. The subjects could stop the test or rest if needed at any point during the 6-minute period, in accordance with the guideline of the American College Society of Medicine (ACSM). ${ }^{27}$

\section{QOL evaluation}

QOL was assessed using a CCQ, ${ }^{28,29}$ which consisted of ten questions in three domains: symptoms (4 items), mental state ( 2 items), and functional state (4 items). Observed symptoms were shortness of breath at rest or while doing physical activities, coughing, and phlegm; mental state was feeling depressed and concerned about breathing; and functional state covered limitations in difficult and different activities of daily life. The questions applied to the week before starting the test or prior to completing the study, and the seven-point scale from zero to six was used. The outcome measurement of CCQ was the total score, calculated as the mean sum of all items, whereas each item was calculated with a higher value presenting lower health status. ${ }^{28}$

\section{Oxidative stress evaluation}

Oxidative stress markers such as TAC, GSH, MDA, and NO were evaluated following the protocols in previous studies. ${ }^{30,31}$ After blood was taken from the anterior cubital vein of each subject and contained in a heparinized tube, $500 \mu \mathrm{L}$ of whole blood was separated by 5, 5'-dithiobis-2-nitrobenzoic acid reagent to determine the GSH. Residual blood was centrifuged at 3,000 rpm for 10 minutes in order to separate fresh plasma for evaluating the TAC, NO, and MDA, using 2, 2'-azinobis(3-ethylbenzothiazoline-6-sulfonic acid) decolorization protocol, Griess reagent, and thiobarbituric acid-reactive substances, respectively. All markers of oxidative stress were evaluated experimentally at the Biomechanics Laboratory of the Department of Physical Therapy, Faculty of Associated Medical Sciences, Chiang Mai University, Thailand.

\section{Dyspnea sensation assay}

Patients feeling subjective dyspnea at rest before and postcompletion of the program and peak dyspnea during device application at week 2, 4, and 6 were interviewed using the 
category ratio scale, with a score from 0 to 10 created using the Borg scale. ${ }^{32}$ All the participants were instructed to report their overall effort in breathing and how difficult that was from the absence of dyspnea ( 0 ) to maximal sensation of dyspnea (10). The 6 weeks of home training was verified by a self-reporting log book and rechecked by caregivers, and re-verified by a physical therapist, every 2 weeks by telephone, and fortnightly through personal appointments at Sansai Hospital.

\section{Statistical analysis}

All the data were analyzed statistically for normal distribution using the one-sample Kolmogorov-Smirnov test before presenting as mean, with standard error or mean, and minimal and maximal values. Characteristics between the three groups were analyzed by the one-way analysis of variance (ANOVA) test. Pulmonary function, PImax, PEmax, QOL, and oxidative stress parameters between the groups were analyzed before and after training by repeated ANOVA measurements ( 3 groups and 2 times) and Bonferroni post hoc test. The dyspnea score was evaluated statistically within the groups by the repeated measurement test before and during the second, fourth, and sixth week of RMT devices, and before completing the protocol at rest. All statistical analyses were carried out using the Statistical Package for Social Science Software version 11.0 (SPSS Inc., Chicago, IL, USA) for Windows. All the tests were performed with significance at $P<0.05$.

\section{Results}

Six of the 36 subjects dropped out of the study before completing the protocol because they discontinued training; therefore, 30 participants completed the study, with 10 participants in each group (Table 1). The three groups were well matched regarding age, weight, height, BMI, and blood pressure, with no significant difference between them.
Results of the pulmonary function and respiratory muscle strength test (Table 2) showed that all variables between the groups presented no statistical difference before training, when evaluated by the one-way ANOVA test (FVC $[P=0.98], \mathrm{FVC} \%[P=0.40], \mathrm{FEV}_{1}[P=0.35], \mathrm{FEV}_{1} \%$ $[P=0.43], \mathrm{FEV}_{1} / \mathrm{FVC}[P=0.53]$, PImax [ $\left.P=0.75\right]$, and PEmax $[P=0.98])$. Standard and prototype RMT devices showed a significant increase of FVC $(P=0.01$ and $P=0.002), \mathrm{FEV}_{1} /$ $\operatorname{FVC}(P=0.031$ and 0.027$), P \operatorname{Imax}(P=0.007$ and 0.000$)$, and PEmax $(P=0.002$ and 0.003$)$ after 6 weeks of training compared to pre-training, except in the control group $(P=0.5$, $0.68,0.59$, and 0.08 , respectively). The $\mathrm{FVC} \%$ results did not increase statistically post-training, compared to before it in both the standard $(P=0.23)$ and prototype groups $(P=0.45)$, as well as the control group $(P=0.68)$ (Table 2$)$, the same as the results of $\mathrm{FEV}_{1}(P=0.18$ and 0.078$)$ and $\mathrm{FEV}_{1} \%(P=0.06$ and 0.11 ) in both groups.

In addition, the results of QOL are shown in Table 3, and consist of total CCQ, symptoms, and mental and function scores, which did not differ statistically between the three groups before training ( $P=0.68,0.75,0.73$, and 0.72 ). However, the standard and prototype devices showed significantly lower total ( $P=0.024$ and 0.032 ), symptom ( $P=0.01$ and 0.02 ), and function ( $P=0.034$ and 0.042$)$ scores after training, but not lower mental score $(P=0.36$ and 0.56$)$. There were no statistical changes in any of these items in the control group (total score, $P=0.52$; symptom, $P=0.35$; mental, $P=0.54$; function, $P=1.00)$. Moreover, results of the 6MWD test showed no statistical changes before or after 6 weeks of training in the control $(P=0.17)$, or standard $(P=0.06)$ or prototype RMT device groups $(P=0.08)$ (Table 3$)$.

All parameters of oxidative stress in the blood (Table 4) before the study had no statistical difference between the three groups (TAC $[P=0.54]$, GSH $[P=0.65]$, MDA $[P=0.72]$, and NO $[P=0.93])$. The standard or prototype device did not affect the TAC $(P=0.62$ and 0.71$)$ or $\mathrm{GSH}(P=0.51$ and 0.45$)$

Table I Characteristics of all participants in the control and standard and prototype RMT device groups

\begin{tabular}{|c|c|c|c|c|}
\hline Parameters & Control $(n=10)$ & Standard RMT $(n=10)$ & Prototype RMT $(n=10)$ & $P$-value \\
\hline Age (years) & $68.75 \pm 2.39(58-70)$ & $63.25 \pm 1.49(58-70)$ & $64.25 \pm 2.5 ।(46-79)$ & 0.38 \\
\hline Sex M:F & $6: 4$ & $4: 6$ & $5: 5$ & - \\
\hline Weight (kg) & $58.8 \pm 6.0(42.0-76.0)$ & $49.4 \pm 4.4(30.5-65.0)$ & $46.2 \pm 3.8(32.0-64.5)$ & 0.18 \\
\hline Height (m) & $1.64 \pm 0.02(1.56-1.74)$ & $1.55 \pm 0.03(1.45-1.68)$ & $1.56 \pm 0.03(1.40-1.68)$ & 0.08 \\
\hline BMI $\left(\mathrm{kg} / \mathrm{m}^{2}\right)$ & $22.1 \pm 2.4(14.8-27.5)$ & $20.6 \pm 1.9(14.3-28.1)$ & $18.98 \pm 1.6(15.6-25.0)$ & 0.53 \\
\hline SBP (mmHg) & $\mid 26.2 \pm 1.6(|2|-\mid 32)$ & $123.8 \pm 2.4(110-132)$ & $123.5 \pm 2.4(|10-13|)$ & 0.55 \\
\hline $\mathrm{DBP}(\mathrm{mmHg})$ & $98.1 \pm 2.8(85.0-100.0)$ & $98.5 \pm 2.9(85.5-105.5)$ & $98.9 \pm 2.1(78.4-100.0)$ & 0.99 \\
\hline
\end{tabular}

Notes: Data are presented as mean \pm standard deviation (minimal and maximal value). $P$-value was analyzed by one-way ANOVA test.

Abbreviations: RMT, respiratory muscle training; M, male; F, female; BMI, body mass index; SBP, systolic blood pressure; DBP, diastolic blood pressure; ANOVA, analysis of variance. 
Table 2 Pulmonary function test and respiratory muscle strength before and after training in the control and standard and prototype device groups

\begin{tabular}{|c|c|c|c|c|c|c|}
\hline \multirow[t]{2}{*}{ Parameters } & \multicolumn{2}{|c|}{ Control $(n=10)$} & \multicolumn{2}{|c|}{ Standard RMT $(n=10)$} & \multicolumn{2}{|c|}{ Prototype RMT $(n=10)$} \\
\hline & Before & After & Before & After & Before & After \\
\hline \multicolumn{7}{|c|}{ Pulmonary function test } \\
\hline FVC (L) & $\begin{array}{l}2.33 \pm 0.14 \\
(1.93-3.13)\end{array}$ & $\begin{array}{l}2.4 I \pm 0.13 \\
(2.10-3.12)\end{array}$ & $\begin{array}{l}2.35 \pm 0.12 \\
(1.60-2.70)\end{array}$ & $\begin{array}{l}2.67 \pm 0.09 * \\
(2.12-2.89)\end{array}$ & $\begin{array}{l}2.29 \pm 0.20 \\
(1.26-3.12)\end{array}$ & $\begin{array}{l}2.63 \pm 0.18^{*} \\
(1.89-3.56)\end{array}$ \\
\hline FVC (\%) & $\begin{array}{l}65.61 \pm 1.68 \\
(55.5-69.5)\end{array}$ & $\begin{array}{l}65.5 \pm 1.30 \\
(57.1-68.6)\end{array}$ & $\begin{array}{l}62.50 \pm 1.75 \\
(56.7-68.0)\end{array}$ & $\begin{array}{l}67.20 \pm 0.69 \\
(64.5-69.5)\end{array}$ & $\begin{array}{l}63.61 \pm 1.39 \\
(56.7-68.4)\end{array}$ & $\begin{array}{l}66.63 \pm 0.52 \\
(64.5-68.3)\end{array}$ \\
\hline $\mathrm{FEV}_{1}(\mathrm{~L})$ & $\begin{array}{l}1.68 \pm 0.12 \\
(1.12-2.15)\end{array}$ & $\begin{array}{l}1.64 \pm 0.13 \\
(1.12-2.10)\end{array}$ & $\begin{array}{l}1.54 \pm 0.11 \\
(1.11-1.98)\end{array}$ & $\begin{array}{l}1.85 \pm 0.07 \\
(1.56-2.12)\end{array}$ & $\begin{array}{l}1.74 \pm 0.05 \\
(1.46-1.99)\end{array}$ & $\begin{array}{l}1.88 \pm 0.08 \\
(1.56-2.21)\end{array}$ \\
\hline $\mathrm{FEV}_{1}(\%)$ & $\begin{array}{l}61.04 \pm 2.19 \\
(50.52-69.36)\end{array}$ & $\begin{array}{l}61.15 \pm 1.68 \\
(52.92-68.72)\end{array}$ & $\begin{array}{l}59.38 \pm 1.47 \\
(53.05-67.45)\end{array}$ & $\begin{array}{l}65.30 \pm 0.83 \\
(62.58-69.66)\end{array}$ & $\begin{array}{l}62.88 \pm 1.86 \\
(53.57-69.96)\end{array}$ & $\begin{array}{l}64.50 \pm 0.84 \\
(60.07-68.19)\end{array}$ \\
\hline $\mathrm{FEV}_{1} / \mathrm{FVC}$ & $\begin{array}{l}0.61 \pm 0.03 \\
(0.46-0.69)\end{array}$ & $\begin{array}{l}0.63 \pm 0.02 \\
(0.54-0.83)\end{array}$ & $\begin{array}{l}0.57 \pm 0.03 \\
(0.43-0.66)\end{array}$ & $\begin{array}{l}0.62 \pm 0.03 * \\
(0.46-0.69)\end{array}$ & $\begin{array}{l}0.58 \pm 0.02 \\
(0.43-0.63)\end{array}$ & $\begin{array}{l}0.68 \pm 0.04 * \\
(0.54-0.82)\end{array}$ \\
\hline \multicolumn{7}{|c|}{ Respiratory muscle strength } \\
\hline $\operatorname{PImax}\left(\mathrm{cmH}_{2} \mathrm{O}\right)$ & $\begin{array}{l}58.87 \pm 6.29 \\
(39-76)\end{array}$ & $\begin{array}{l}60.87 \pm 4.39 \\
(39-76)\end{array}$ & $\begin{array}{l}54.0 \pm 5.16 \\
(35-84)\end{array}$ & $\begin{array}{l}84.0 \pm 7.07 * \\
(39-104)\end{array}$ & $\begin{array}{l}53.50 \pm 5.20 \\
(38-76)\end{array}$ & $\begin{array}{l}83.6 \pm 4.40 * \\
(68-101)\end{array}$ \\
\hline $\operatorname{PEmax}\left(\mathrm{cmH}_{2} \mathrm{O}\right)$ & $\begin{array}{l}74.12 \pm 6.08 \\
(53-99)\end{array}$ & $\begin{array}{l}76.1 \pm 6.08 \\
(54-102)\end{array}$ & $\begin{array}{l}72.62 \pm 7.05 \\
(45-I I 2)\end{array}$ & $\begin{array}{l}97.5 \pm 8.3 I^{*} \\
(76-132)\end{array}$ & $\begin{array}{l}73.4 \pm 6.49 \\
(45-110)\end{array}$ & $\begin{array}{l}93.5 \pm 7.32 * \\
(6 I-123)\end{array}$ \\
\hline
\end{tabular}

Notes: Data are expressed as mean \pm standard error of mean (min-max). $* P<0.05$ compared to pre-training in each group.

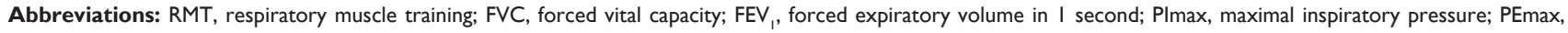
maximal expiratory pressure; min, minimum; max, maximum.

Table 3 Quality of life and 6MWD before and after training in the control and standard and prototype device groups

\begin{tabular}{|c|c|c|c|c|c|c|}
\hline \multirow[t]{2}{*}{ Parameters } & \multicolumn{2}{|c|}{ Control $(n=10)$} & \multicolumn{2}{|c|}{ Standard RMT $(n=10)$} & \multicolumn{2}{|c|}{ Prototype RMT $(n=10)$} \\
\hline & Before & After & Before & After & Before & After \\
\hline \multicolumn{7}{|l|}{ Quality of life } \\
\hline Total score & $\begin{array}{l}1.55 \pm 0.34 \\
(0.8-3.4)\end{array}$ & $\begin{array}{l}1.57 \pm 0.34 \\
(0.4-3.4)\end{array}$ & $\begin{array}{l}2.02 \pm 0.21 \\
(I . I-3.2)\end{array}$ & $\begin{array}{l}1.12 \pm 0.37^{*} \\
(0.2-3.1)\end{array}$ & $\begin{array}{l}\text { I.86 } 80.32 \\
(0.4-3.4)\end{array}$ & $\begin{array}{l}1.20 \pm 0.19 * \\
(0.5-1.9)\end{array}$ \\
\hline Symptom score & $\begin{array}{l}2.62 \pm 0.37 \\
(1.5-5.0)\end{array}$ & $\begin{array}{l}2.4 I \pm 0.42 \\
(I .0-5.0)\end{array}$ & $\begin{array}{l}3.30 \pm 0.30 \\
(2.0-4.5)\end{array}$ & $\begin{array}{l}I .8 I \pm 0.49 * \\
(0.5-4.24)\end{array}$ & $\begin{array}{l}2.79 \pm 0.45 \\
(0.5-5.0)\end{array}$ & $\begin{array}{l}1.56 \pm 0.37 * \\
(0.0-3.5)\end{array}$ \\
\hline Mental score & $\begin{array}{l}1.25 \pm 0.29 \\
(0.0-2.5)\end{array}$ & $\begin{array}{l}1.06 \pm 0.35 \\
(0.0-2.5)\end{array}$ & $\begin{array}{l}\text { I.I3 } 13.34 \\
(0.0-3.0)\end{array}$ & $\begin{array}{l}0.89 \pm 0.32 \\
(0.0-2.5)\end{array}$ & $\begin{array}{l}1.06 \pm 0.36 \\
(0.0-2.5)\end{array}$ & $\begin{array}{l}0.87 \pm 0.27 \\
(0.0-2.0)\end{array}$ \\
\hline Function score & $\begin{array}{l}0.97 \pm 0.25 \\
(0.0-2.2)\end{array}$ & $\begin{array}{l}0.97 \pm 0.20 \\
(0.0-2.2)\end{array}$ & $\begin{array}{l}1.22 \pm 0.29 \\
(0.5-3.0)\end{array}$ & $\begin{array}{l}0.56 \pm 0.34^{*} \\
(0.0-2.7)\end{array}$ & $\begin{array}{l}1.28 \pm 0.30 \\
(0.0-2.2)\end{array}$ & $\begin{array}{l}0.87 \pm 0.28^{*} \\
(0.0-2.0)\end{array}$ \\
\hline 6MWD (m) & $\begin{array}{l}291.9 \pm 26.1 \\
(229.0-425.0)\end{array}$ & $\begin{array}{l}318.9 \pm 21.1 \\
(242.5-4 \mid 2.5)\end{array}$ & $\begin{array}{l}300.4 \pm 18.1 \\
(225.5-345.5)\end{array}$ & $\begin{array}{l}340.0 \pm 17.7 \\
(286.5-399.0)\end{array}$ & $\begin{array}{l}294.2 \pm 25.9 \\
(225.5-434.5)\end{array}$ & $\begin{array}{l}331.5 \pm 24.8 \\
(250.5-481.5)\end{array}$ \\
\hline
\end{tabular}

Notes: Data are expressed as mean \pm standard error of mean (min-max). $* \mathrm{P}<0.05$ compared to pre-training in each group.

Abbreviations: 6MWD, 6-minute walking distance; min, minimum; max, maximum.

Table 4 Oxidative stress markers (TAC, GSH, MDA, and NO) before and after training in the control and standard and prototype device groups

\begin{tabular}{|c|c|c|c|c|c|c|}
\hline \multirow[t]{2}{*}{ Parameters } & \multicolumn{2}{|c|}{ Control $(n=10)$} & \multicolumn{2}{|c|}{ Standard RMT $(n=10)$} & \multicolumn{2}{|c|}{ Prototype RMT $(n=10)$} \\
\hline & Before & After & Before & After & Before & After \\
\hline TAC (mmol Trolox/L) & $\begin{array}{l}2.24 \pm 0.09 \\
(1.85-2.65)\end{array}$ & $\begin{array}{l}2.15 \pm 0.14 \\
(1.34-2.56)\end{array}$ & $\begin{array}{l}2.58 \pm 0.11 \\
(1.95-3.11)\end{array}$ & $\begin{array}{l}2.30 \pm 0.17 \\
(1.45-3.12)\end{array}$ & $\begin{array}{l}2.08 \pm 0.11 \\
(1.56-2.69)\end{array}$ & $\begin{array}{l}2.15 \pm 0.14 \\
(1.55-2.67)\end{array}$ \\
\hline GSH (mg/dL) & $\begin{array}{l}3.12 \pm 0.16 \\
(2.13-3.95)\end{array}$ & $\begin{array}{l}3.08 \pm 0.16 \\
(2.45-3.56)\end{array}$ & $\begin{array}{l}3.36 \pm 0.18 \\
(2.56-3.95)\end{array}$ & $\begin{array}{l}3.27 \pm 0.14 \\
(2.67-3.91)\end{array}$ & $\begin{array}{l}3.24 \pm 0.20 \\
(2.12-3.95)\end{array}$ & $\begin{array}{l}3.40 \pm 0.20 \\
(2.45-4.54)\end{array}$ \\
\hline $\operatorname{MDA}(\mu \mathrm{mol} / \mathrm{L})$ & $\begin{array}{l}4.50 \pm 0.16 \\
(2.45-3.56)\end{array}$ & $\begin{array}{l}4.25 \pm 0.41 \\
(3.87-4.87)\end{array}$ & $\begin{array}{l}4.35 \pm 0.31 \\
(3.67-4.78)\end{array}$ & $\begin{array}{l}2.24 \pm 0.17^{*} \\
(1.34-3.12)\end{array}$ & $\begin{array}{l}4.36 \pm 0.12 \\
(3.65-4.11)\end{array}$ & $\begin{array}{l}2.97 \pm 0.16^{*} \\
(1.72-3.21)\end{array}$ \\
\hline $\mathrm{NO}(\mu \mathrm{mol} / \mathrm{L})$ & $\begin{array}{l}7.16 \pm 0.59 \\
(5.12-10.12)\end{array}$ & $\begin{array}{l}7.65 \pm 0.81 \\
(4.32-11.2)\end{array}$ & $\begin{array}{l}7.54 \pm 0.86 \\
(5.5-12.3)\end{array}$ & $\begin{array}{l}14.13 \pm 1.33 * \\
(9.12-20.12)\end{array}$ & $\begin{array}{l}7.25 \pm 0.73 \\
(5.12-10.12)\end{array}$ & $\begin{array}{l}13.56 \pm 1.11 * \\
(10.12-18.12)\end{array}$ \\
\hline
\end{tabular}

Notes: Data are expressed as mean \pm standard error of mean (min-max). $* P<0.05$ compared to pre-training in each group.

Abbreviations: TAC, total antioxidant capacity; GSH, glutathione; MDA, malondialdehyde; NO, nitric oxide; RMT, respiratory muscle training; min, minimum; max, maximum. 


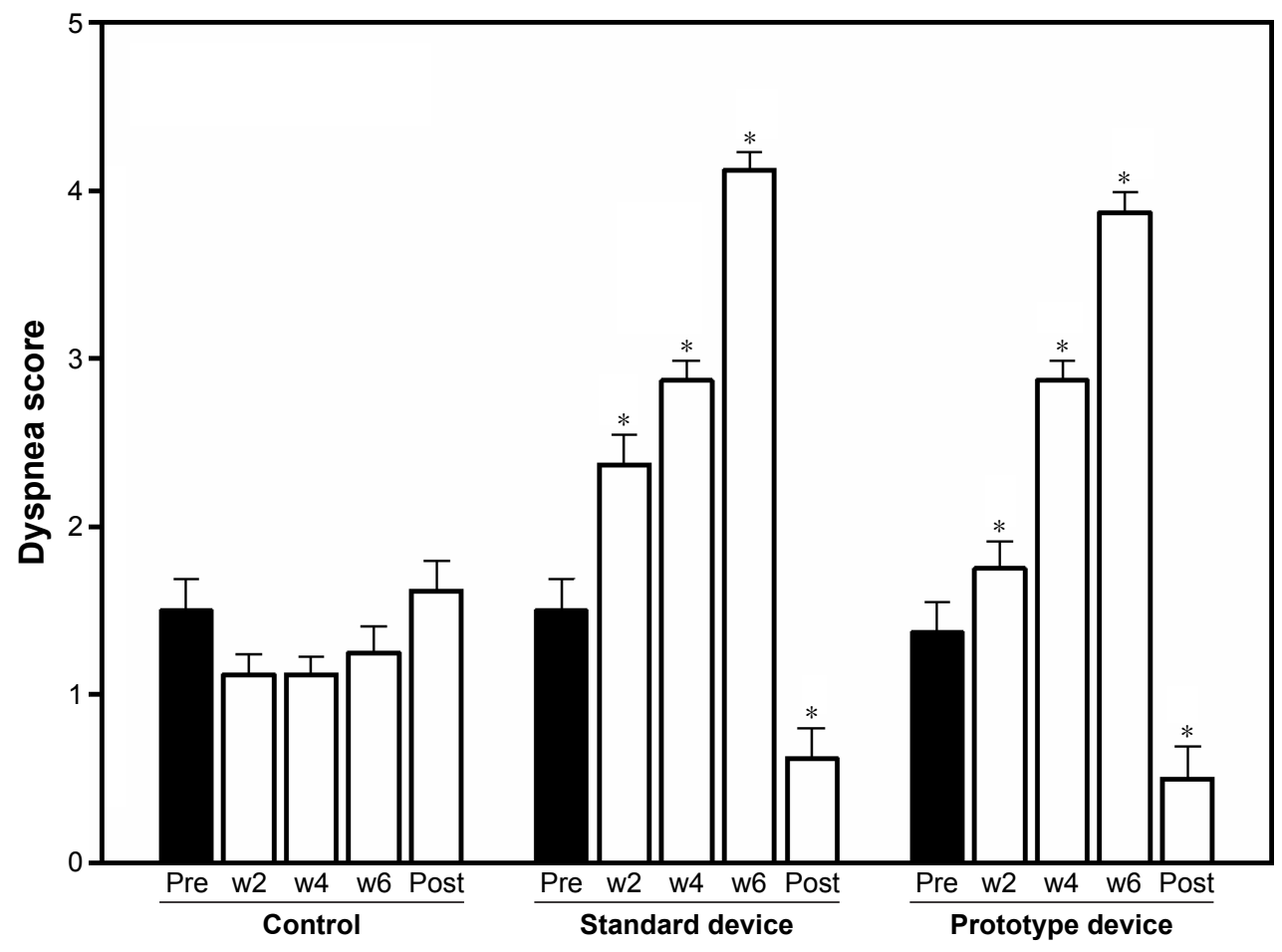

Figure 2 Dyspnea score between the three groups; control and standard and prototype RMT device groups before training (Pre), at week 2 (w2), week 4 (w4), week 6 (w6), and at rest after completing the study (Post). $* P<0.01$ was compared to pre-training (Pre) using the post hoc Bonferroni test.

Abbreviation: RMT, respiratory muscle training.

compared to pre-training, as in the control group ( $P=0.51$ and 0.76). However, the MDA level decreased significantly after training in the standard and prototype device groups, compared to before training ( $P=0.000$ and 0.001$)$. Furthermore, NO increased significantly after training with the standard and prototype devices $(P=0.001$ and 0.00$)$, whereas no changes occurred in either MDA $(P=0.13)$ or $\mathrm{NO}(P=0.14)$ in the control group.

The result of dyspnea score between the three groups showed no statistical difference before training $(P=0.11)$. Use of either the standard or prototype RMT device presented significantly high dyspnea score in week $2(P=0.000$ and 0.000$),(P=0.000$ and $P=0.000)$ and $6(P=0.000$ and $P=0.000)$, compared to pre-training. However, the dyspnea scores at rest showed a significantly lower score after completing 6 weeks of training, compared to before training (standard device; $0.62 \pm 0.18$ and $1.5 \pm 0.19, P=0.006$ and prototype device; $0.50 \pm 0.19$ and $1.37 \pm 0.18, P=0.001$ ). No statistical changes occurred during four periods in the control group $(1.5 \pm 0.19,1.12 \pm 0.12,1.12 \pm 0.11,1.25 \pm 0.16$, and $1.62 \pm 0.18 ; P=1.00$ ) (Figure 2).

\section{Discussion}

The aim of this preliminary study was to propose the possible application of a simple prototype device for training the respiratory muscles in COPD subjects. However, this study recruited a small number of male and female COPD patients, due to the limited availability of moderate COPD subjects. Twelve subjects were included in each of the three groups initially, but only 10 participants in each group completed the program. After a one-way ANOVA was used for statistical analysis the characteristic parameter as weight, height, BMI, or systolic or diastolic blood pressure before starting the protocol, there did not significant difference between three groups. Therefore confounding factors were initially excluded and provided the validity of the results after complete the training program. All data showed normal distribution before and after the training periods, due to non-significant results of the one-sample Kolmogorov-Smirnov test $(P>0.05)$.

This experimental design applied the prototype or standard RMT device with three different diameter holes of 6,4 , and 2 $\mathrm{mm}$ in 2 week periods of 6 weeks of training. Each diameter size was used daily for 7 days as a pilot proposal for each period. Previous reports suggested that the training period for improving respiratory muscles is dominant at $4-8$ weeks. ${ }^{33,34}$ Although previous evidence had proposed that the training intensity in healthy people should exceed $50 \%$ of MIP, at a frequency of once or twice daily for 5-7 days, ${ }^{21}$ and the muscle function could adapt significantly within 3 weeks after training. ${ }^{35}$ Changes in strength that occur within the first 2 
weeks of training have been attributed traditionally to a neural adaptation process. ${ }^{36}$ Therefore, a 6-week intervention was designed in this study. On the other hand, because of unknown resistive pressure or resistance percentage in the standard RMT device, starting with a low resistor of $6 \mathrm{~mm}$ diameter, and possibly increasing to a harder one of 4 and $2 \mathrm{~mm}$ diameter, is recommended, unless the criterion for stopping the exercise presents itself, such as severe dyspnea, fatigue, or unstable vital signs, according to the ACSM guideline. ${ }^{27}$ Therefore, this preliminary study was designed to compare RMT devices with low resistance at $6 \mathrm{~mm}$ diameter in the first 2 weeks, increased resistance in the second week at $4 \mathrm{~mm}$ diameter, and finally most resistance at $2 \mathrm{~mm}$ diameter after completing 4 weeks of training. Regarding the RMT protocol in both devices, subjects should be instructed to exhale as much as possible before inhaling, which is consistent with previous evidence in maneuver device training. ${ }^{37}$ Moreover, four sessions of thirty repeated inspirations and a 3-minute rest period was designed in this training program within a total duration of 20 minutes of exercise. Although a previous report stated that 30 single breaths with moderate load improved endurance significantly in healthy people, ${ }^{38}$ some studies presented a non-significant controversial improvement from a low $15 \%$ of MIP. ${ }^{39-41}$ Thus, four repeated sessions of 30 breaths per day for 7 days was possibly enough muscle work to gain respiratory muscle strength. However, this protocol still needs more study and confirmation in the future. A previous report suggested that 30 minutes of training for 5 days per week at a load of $40 \%-50 \%$ of MIP in COPD patients, ${ }^{42}$ or 30 minutes of daily training at $30 \%$ of MIP for 4 weeks in patients with chronic heart failure, could be carried out. ${ }^{43}$ However, this study conducted 20 minutes of training for 7 days per week for 6 weeks, and presented possible benefits for respiratory muscle strength.

The results of this study showed that the PImax and PEmax values increased significantly when applied to both RMT devices, whereas no changes occurred in the control group. Interesting pulmonary function results in this study showed that $\mathrm{FVC}$ and $\mathrm{FEV}_{1} / \mathrm{FVC}$ also presented a significant increase, but the $\mathrm{FVC} \%$ or $\mathrm{FEV}_{1}$ and $\mathrm{FEV}_{1} \%$ did not change. The case of non-significant changes is similar to that in a previous study of COPD patients who were diagnosed with moderately severe stage. ${ }^{44}$

The St George's Respiratory Questionnaire and BODE index were applied in part of the QOL evaluation for detecting efficiency of the RMT among COPD patients, but more time was spent on evaluating the limitation. ${ }^{45}$ Moreover, the chronic respiratory questionnaire self-report (CRQ-SR) and other HRQoL instruments used in clinical study also are extensive instruments that spend more time on evaluation. ${ }^{45}$ Thus, the CCQ was used in this study with 10 short questions on three items: symptoms, mental state, and function evaluation, which present good internal consistency (Cronbach's alpha $>70 \%$ ) compared to the CRQ-SR. ${ }^{28}$ In addition, the CCQ proved to correlate with the St George's Respiratory Questionnaire, generic HRQL instrument SF-36 ${ }^{\circledR},{ }^{29}$ and CRQ-SR. ${ }^{28}$ Interesting data from a study updated in 2012 showed that the final low CCQ score was associated with low HRQoL and high mortality risk in COPD patients. ${ }^{46}$ The CCQ from this study, with its brevity and simplicity, makes it a translatable Thai version, and was suitable for routine use in this study. The CCQ results of total and symptom and function scores improved in both training groups, but no changes occurred in the control group, especially regarding symptom and function scores. Therefore, the efficiency of RMT training by the prototype device was presented as the same as that of the standard device, meaning application of this prototype is possible in the future.

Data for the 6MWD results showed an increase before and after 6 weeks of training, but findings from statistical analysis were not different between the three groups during the same period. This means that there were no changes when training with either standard or prototype device, which was the same in the control group. Previous evidence has claimed that the clinically important difference for 6MWD should be $53 \mathrm{~m},{ }^{47}$ while updated meta-analysis suggested that $32 \mathrm{~m}$ can predict a clinically important difference. Furthermore, a previous study by Hill et al reported a mean baseline distance of $446 \mathrm{~m}$ in the 6-minute walking test (6MWT), increasing to $473 \mathrm{~m}$ post-training in the RMT group. ${ }^{48}$ The study by Koppers et al reported a mean baseline distance of $512 \mathrm{~m}$ in the 6MWT, improving to $535 \mathrm{~m}$ post-training in the RMT group. ${ }^{49}$ However, neither study could assume that the change in distance represented clinical improvement. In this study, a difference of approximately 30-40 m distance did not present a statistical difference between pre-training and post-training in both RMT training groups, and also in the control group. Therefore, different changes below $53 \mathrm{~m}$ may not be a response to change in either a statistical tool or clinical improvement, as suggested previously. ${ }^{47}$

When dyspnea scores were observed in both training groups, they were significant at week 4 and 6, compared to baseline. Precautions from harmful exercise are taken in cases of dyspnea, especially in the COPD clinic. Although this assessment tool is subjective, ${ }^{50}$ it can be used to represent the intensity of overload during exercise in patients with COPD. ${ }^{51}$ 
Previous evidence has claimed the possibility of dyspnea from respiratory muscle dysfunction, and that free radicals can be produced during muscle contraction..$^{52}$ Assessment on dyspnea during the use of an RMT device is a simple and gold standard protocol for evaluating respiratory impairment or maximal capacity during exercise, especially by a respiratory therapist,${ }^{53}$ and it can present the benefits of the pulmonary rehabilitation program either in the hospital ${ }^{54}$ or at home. ${ }^{55}$

Moreover, a previous study reported oxidant-anti-oxidant imbalance in COPD patients, and the results found low TAC, GSH, and NO levels and a high level of MDA in the patients. ${ }^{56}$ Therefore, the possible influence of over RMT training with standard or prototype devices may induce oxidative stress that this study had be concerned. The results of this preliminary study showed that the TAC and GSH levels did not change significantly, except MDA and NO levels. Few reviews of previous articles showed reports of RMT effects on oxidative stress. However, an updated report indicated that some deleterious effects induced NO synthase activity in the respiratory tract during an asthma attack in order to release NO and superoxide. ${ }^{57}$ However, all the subjects in this study had no recurrent exacerbation; thus, increasing the NO level was not possible from recurrent exacerbation or attack. Nevertheless, changes in the MDA and NO levels after 6 weeks of training could have reflected from RMT training. In addition, increasing FVC and PImax or PEmax after training showed improvement in lung volume, but how the MDA level reduced and NO level improved are still unclear. Although the 6MWD test presented increases in all three groups, control (291-318 m, $27 \mathrm{~m}$ distance change), standard device (300-340 m, $40 \mathrm{~m}$ distance change), and prototype device (294-331 m, $37 \mathrm{~m}$ distance change), both devices produced more distance change than that in the control group, which was possibly due to an increasing level of NO. These results possibly explain, as do previous studies, the significant correlation between the 6MWD and NO level in elderly subjects. ${ }^{31}$ Although there were no healthy subjects in the control group, previous evidence showed that their NO level $(12.30 \pm 1.25 \mu \mathrm{mol} / \mathrm{L})$ and 6MWD $(348.17 \pm 41.81 \mathrm{~m})$ were higher than those in this study's COPD control group $(7.54 \pm 0.56 \mu \mathrm{mol} / \mathrm{L})$. Therefore, NO claims to have effect on vasodilation, ${ }^{58}$ and helps to increase blood flow in the muscle, which possibly increases walking capacity. Interesting results of lower dyspnea score, after 6 weeks of training with both devices, showed clinical benefits that were similar to those from previous evidence, as reviewed from many studies. ${ }^{19}$ Thus, RMT improves respiratory muscle strength and reduces dyspnea in COPD patients. Overall results in this study show that changes of FVC, $\mathrm{FEV}_{1} / \mathrm{FVC}$, PImax, PEmax, QOL, and dyspnea score are similar between training with a simple prototype device and a standard RMT device. Therefore, application of this simple prototype device can be suggested for use in the clinic because of cheaper price (less than US\$2 per set) and possibly challenging for many developing countries those with a low economy.

\section{Clinical application and limitations}

The prototype device for training pulmonary function and respiratory muscles is simple, cheap, and easy to make from a plastic water pipe and plastic caps. The 6-week training period demonstrated some clinical improvement. Moreover, the results obtained from a small sample size of subjects and unknown the percentage of resistive pressure in both devices that is limitations. Therefore, this device may not be applied directly to other COPD patients who need inspiratory muscle training. Future research regarding the study of COPD patients, with a larger sample size and varied severity, is needed. However, this prototype device is a possible model for applying to RMT in an urban community, which has limited economic status and possibly commercial agencies. On the other hand, it also needs to have manufacturing standards of good consistency and validity before achieving wide distribution in general hospitals or urban communities.

\section{Acknowledgments}

This study received a grant from the Research Center in Back, Neck, Other Joint Pain and Human Performance (BNOJPH), Khon Kaen University, Khon Kaen, Thailand. The authors thank all the subjects, caregivers, and physical therapists at Sansai Hospital for their assistance in helping to control and organize the training with good consistency. The authors also thank all the physical therapists at Sansai Hospital, Chiang Mai Province, for organizing space to collect data.

\section{Disclosure}

The authors report no conflicts of interest in this work.

\section{References}

1. Rabe KF, Hurd S, Anzueto A, et al; Global Initiative for Chronic Obstructive Lung Disease. Global strategy for the diagnosis, management, and prevention of chronic obstructive pulmonary disease: GOLD executive summary. Am J Respir Crit Care Med. 2007;176(6):532-555.

2. Pothirat C, Chaiwong W, Phetsuk N, Pisalthanapuna S, Chetsadaphan N, Inchai J. A comparative study of COPD burden between urban vs rural communities in northern Thailand. Int J Chron Obstruct Pulmon Dis. 2015;10:1035-1042.

3. Domej W, Oettl K, Renner W. Oxidative stress and free radicals in COPD-implications and relevance for treatment. Int J Chron Obstruct Pulmon Dis. 2014;9:1207-1224. 
4. Kirkham P, Rahman I. Oxidative stress in asthma and COPD: antioxidants as a therapeutic strategy. Pharmacol Ther. 2006;111(2):476-494.

5. Ahmad A, Shameem M, Husain Q. Altered oxidant-antioxidant levels in the disease prognosis of chronic obstructive pulmonary disease. Int J Tuberc Lung Dis. 2013;17(8):1104-1109.

6. Nadeem A, Raj HG, Chhabra SK. Increased oxidative stress and altered levels of antioxidants in chronic obstructive pulmonary disease. Inflammation. 2005;29(1):23-32.

7. Rahman I, Morrison D, Donaldson K, MacNee W. Systemic oxidative stress in asthma, COPD, and smokers. Am J Respir Crit Care Med. 1996; 154(4 Pt 1):1055-1060.

8. Barreiro E. Protein carbonylation and muscle function in COPD and other conditions. Mass Spectrom Rev. 2014;33(3):219-236.

9. Zuo L, Best TM, Roberts WJ, Diaz PT, Wanger PD. Characterization of reaction oxygen species in diaphragm. Acta Physiol (Oxf). 2015; 213(3):700-710

10. Zuo L, Hallman AH, Roberts WJ, Wagner PD, Hogan MC. Superoxide release from contracting skeletal muscle in pulmonary TNF- $\alpha$ overexpression mice. Am J Physiol Regul Integr Comp Physiol. 2014; 306(1):R75-R81.

11. Zuo L, Shiah A, Roberts WJ, Chien MT, Wagner PD, Hogan MC. Low $\mathrm{PO} 2$ conditions induce oxygen reactive oxygen species formation during contractions in single skeletal muscle fibers. Am J Physiol Regul Integr Comp Physiol. 2013;304(11):R1009-R1016.

12. Lacasse Y, Martin S, Lasserson TJ, Goldstein RS. Meta-analysis of respiratory rehabilitation in chronic obstructive pulmonary disease. A Cochrane systematic review. Eura Medicophys. 2007;43(4):475-485.

13. Riario-Sforza GG, Incorvaia C, Paterniti F, et al. Effects of pulmonary rehabilitation on exercise capacity in patients with COPD: A number needed to treat study. Int J Chron Obstruct Pulmon Dis. 2009;4: 315-319.

14. Ries AL, Bauldoff GS, Carlin BW, et al. Pulmonary rehabilitation; Joint ACCP/AACVPR Evidence-based clinical practice guidelines. Chest. 2007;313(5 Suppl):4S-42S.

15. Mikelsons C. The role of physiotherapy in the management of COPD. Respir Med: COPD Update. 2008;4(1):2-7.

16. Mercken EM, Hageman GJ, Schols AM, Akkemans MA, Bast A, Wouters EF. Rehabilitation decreases exercise-induced oxidative stress in chronic obstructive pulmonary disease. Am J Respir Crit Care Med. 2005;172(8):994-1001.

17. Viña J, Servera E, Asensi M, et al. Exercise causes blood glutathione oxidation in chronic obstructive pulmonary disease: prevention by $\mathrm{O}_{2}$ therapy. J Appl Physiol (1985). 1996;81(5):2198-2202.

18. Heunks LM, Viña J, van Herwaarden CL, Folgering HT, Gimeno A, Dekhuijzen PN. Xanthine oxidase is involved in exercise-induced oxidative stress in chronic obstructive pulmonary disease. Am J Physiol. 1999; 277(6 Pt 2):R1697-R1704.

19. Geddes EL, Reid WD, Crowe J, O’Brien K, Brooks D. Inspiratory muscle training in adults with chronic obstructive pulmonary disease: a systematic review. Respir Med. 2005;99(11):1440-1458.

20. McCool FD, Tzelepis GE. Dysfunction of the diaphragm. $N$ Engl $J$ Med. 2012;366(10):932-942.

21. McConnell AK, Romer LM. Respiratory muscle training in healthy humans: resolving the controversy. Int J Sports Med. 2004;25(4): 284-293.

22. Beaumont $\mathrm{M}$, Mialon $\mathrm{P}$, Le Ber-Moy $\mathrm{C}$, et al. Inspiratory muscle training during pulmonary rehabilitation in chronic obstructive pulmonary disease: A randomized trial. Chron Respir Disease. 2015;12:305-312.

23. Global Initiative for Chronic Obstructive Lung Disease. Global strategy for the diagnosis, management and prevention of chronic obstructive pulmonary disease (update 2011). Available from: www.goldcopd.com. Accessed February 21, 2014.

24. Griffiths LA, McConnell AK. The influence of inspiratory and expiratory muscle training upon rowing performance. Eur J Appl Physiol. 2007; 99(5):457-466.

25. Standardization of spirometry - 1987 update. Statement of the American Thoracic Society. Am Rev Respir Dis. 1987;136(5):1285-1298.
26. ATS Committee on Proficiency Standards for Clinical Pulmonary Function Laboratories. ATS statement: guidelines for six-minute walk test. Am J Respir Crit Care Med. 2002;166(1):111-117.

27. American College of Sport Medicine (ACSM). ACSM's guidelines for exercise testing and prescription. Philadelphia, PA: Lippincott Williams \& Wilkins; 2004:110-112.

28. Reda AA, Kotz D, Kocks JW, Wesseling G, van Schayck CP. Reliability and validity of the clinical COPD questionnaire and chronic respiratory questionnaire. Respir Med. 2010;104(11):1675-1682.

29. van der Molen T, Willemse BW, Schokker S, ten Hacken NH, Postma DS, Juniper EF. Development, validity and responsiveness of the Clinical COPD Questionnaire. Health Qual Life Outcomes. 2003;1:13.

30. Leelarungrayub J, Yankai A, Pinkaew D, Puntumetakul R, Laskin JJ, Bloomer RJ. A preliminary study on the effects of star fruit consumption on antioxidant and lipid status in elderly Thai individuals. Clin Interv Aging. 2016;11:1183-1192.

31. Leelarungrayub J, Laskin JJ, Bloomer RJ, Pinkaew D. Consumption of star fruit on pro-inflammatory markers and walking distance in the community dwelling elderly. Arch Gerontol Geriatr. 2016;64:6-12.

32. Borg G. Borg's perceived exertion and pain scales. Champaign, IL: Human Kinetics; 1998

33. Enright SJ, Unnithan VB, Heward C, Withnall L, Davies DH. Effect of high-intensity inspiratory muscle training on lung volumes, diaphragm thickness, and exercise capacity in subjects who are healthy. Phys Ther. 2006;86(3):345-354.

34. Downey AE, Chenoweth LM, Townsend DK, Ranum JD, Ferguson CS, Harms CA. Effects of inspiratory muscle training on exercise responses in normoxia and hypoxia. Respir Physiol Neurobiol. 2007;156(2): 137-146.

35. Romer LM, McConnell AK. Specificity and reversibility of inspiratory muscle training. Med Sci Sports Exerc. 2003;35:237-244.

36. Jones DA, Rutherford OM, Parker DF. Physiological changes in skeletal muscle as a result of strength training. Q J Exp Physiol. 1989;74(3): 233-256.

37. Tzelepis GE, Vega DL, Cohen ME, McCool FD. Lung volume specificity of inspiratory muscle training. J Appl Physiol (1985). 1994;77(2): 789-794.

38. Caine MP, McConnell AK. The inspiratory muscle can be trained differentially to increase strength or endurance using a pressure threshold, inspiratory muscle training device. Eur Respir J. 1998;12:58-59.

39. Bailey SJ, Romer LM, Kelly J, Wilkerson DP, DiMenna FJ, Jones AM. Inspiratory muscle training enhances pulmonary $\mathrm{O}_{2}$ uptake kinetics and high-intensity exercise tolerance in humans. J Appl Physiol (1985). 2010;109(2):457-468.

40. Brown PI, Sharpe GR, Johnson MA. Inspiratory muscle training abolishes the blood lactate increase associated with volitional hyperpnoea superimposed on exercise and accelerates lactate and oxygen uptake kinetics at the onset of exercise. Eur J Appl Physiol. 2012;112(6): 2117-2129.

41. Turner LA, Tecklenburg-Lund SL, Chapman RF, Stager JM, Wilhite DP, Mickleborough TD. Inspiratory muscle training lowers the oxygen cost of voluntary hyperpnea. J Appl Physiol (1985). 2012; 112(1):127-134.

42. Ramirez-Sarmiento A, Orozco-Levi M, Guell R, et al. Inspiratory muscle training in patients with chronic obstructive pulmonary disease: structural adaptation and physiologic outcomes. Am J Respir Crit Care Med. 2002;166(11):1491-1497.

43. Chiappa GR, Roseguini BT, Vieira PJ, et al. Inspiratory muscle training improves blood flow to resting and exercising limbs in patients with chronic heart disease. J Am Coll Cardiol. 2008;51(17):1663-1671.

44. Khalil M, Wagih K, Mahmoud O. Evaluation of maximum inspiratory and expiratory pressure in patients with chronic obstructive pulmonary disease. Egypt J Chest Dis Tuberc. 2014;63(2):329-335.

45. Elmorsi AS, Eldesoky ME, Abdelwahab Mohsen MA, Shalaby NM, Abdalla DA. Effect of inspiratory muscle training on exercise performance and quality of life in patients with chronic obstructive pulmonary disease. Egypt J Chest Dis Tuberc. 2016;65(1):41-46. 
46. Sundh J, Janson C, Lisspers K, Montgomery S, Ställberg B. Clinical COPD questionnaire score (CCQ) and mortality. Int J Chron Obstruct Pulmon Dis. 2012;7:833-842.

47. Redelmeier DA, Bayoumi AM, Goldstein RS, Guyatt GH. Interpreting small differences in functional status: the Six Minute Walk Test in chronic obstructive lung disease patients. Am J Respir Crit Care Med. 1997;155(4):1278-1282.

48. Hill K, Jenkins SC, Phiippe DL, et al. High-intensity inspiratory muscle training in COPD. Eur Respir J. 2006;27(6):1119-1128.

49. Koppers RJ, Vos PJ, Boot CR, Foldering HT. Exercise performance improves in patients with COPD due to respiratory muscle endurance training. Chest. 2006;129(4):886-892.

50. Dyspnea: mechanisms, assessment, and management: a consensus statement. Am J Respir Crit Care Med. 1999;159(1):321-340.

51. Fierro-Carrion G, Mahler DA, Ward J, Baird JC. Comparison of continuous and discrete measurements of dyspnea during exercise in patients with COPD and normal subjects. Chest. 2004;125(1):77-84.

52. Heunks LM, Dekhuijzen PN. Respiratory muscle function and free radicals: from cell to COPD. Thorax. 2000;55(8):704-716.
53. Karampela I, Hansen-Flachen J, Smith S, Reily D, Fuchs BD. A dyspnea evaluation protocol for respiratory therapists: a feasibility study. Respir Care. 2002;47(10):1158-1161.

54. Leelarungrayub J, Pinkaew D, Wonglangka K, Eungpichichpong W, Klapajone J. Short-term pulmonary rehabilitation for a female patient with chronic scleroderma under a single-case research design. Clin Med Insights Circ Respir Pulm Med. 2016;10:11-17.

55. Afolabi G, Stevens R, Turner M, et al. Development of a pulmonary rehabilitation service for people with COPD: a tiered model of integrated care. J Cardipulm Rehabil Prev. 2013;33:323-327.

56. ben Anes A, Fetoul H, Bchir S, et al. Increased oxidative stress and altered levels of nitric oxide and peroxynitrite in Tunisian patients with chronic obstructive pulmonary disease: Correlation with disease severity and airflow obstruction. Biol Trace Elem Res. 2014;161(1):20-31.

57. Zuo L, Koozechian MS, Chen LL. Characterization of reactive nitrogen species in allergic asthma. Ann Allergy Asthma Immunol. 2014;112(1): 18-22.

58. Mutchler SM, Straub AC. Compartmentalized nitric oxide signaling in the resistance vasculature. Nitric Oxide. 2015;49:8-15.
International Journal of COPD

\section{Publish your work in this journal}

The International Journal of COPD is an international, peer-reviewed journal of therapeutics and pharmacology focusing on concise rapid reporting of clinical studies and reviews in COPD. Special focus is given to the pathophysiological processes underlying the disease, intervention programs, patient focused education, and self management protocols.

\section{Dovepress}

This journal is indexed on PubMed Central, MedLine and CAS. The manuscript management system is completely online and includes a very quick and fair peer-review system, which is all easy to use. Visit http://www.dovepress.com/testimonials.php to read real quotes from published authors.

Submit your manuscript here: http://www.dovepress.com/international-journal-of-chronic-obstructive-pulmonary-disease-journal 